\title{
Effects of Injection Molding Process Conditions on Physical Properties of EPDM Using Design of Experiment Method
}

\author{
Young Shin Kim ${ }^{1}$, Euy Sik Jeon ${ }^{2, a}$ and Eui Seob Hwang ${ }^{3}$ \\ ${ }^{1}$ Industrial Technology Research Institute, Kongju National University, Korea \\ ${ }^{2}$ Department of Mechanical Engineering, Graduate School (Industrial Technology Research Institute), Kongju \\ National University, Korea \\ ${ }^{3}$ New Business department Daesung Hi Tech, Korea
}

\begin{abstract}
The process variables such as time and temperature during the EPDM-injection molding not only change the physical properties of the raw material but also affect the insertion and separations forces when a grommet product is molded and mounted on a car body. Using the design of experiments method, the major factors in the injection molding process were considered to analyze their effects on the physical properties of the obtained EPDM materials. Test pieces were prepared under different process conditions, tensile strength and elongation were measured, and their correlation was analyzed.
\end{abstract}

\section{Introduction}

Grommets are a major component of automobiles, where they provide a proper setting of the external and internal cables. They are mainly made of maleated polymer-grafted ethylene propylene diene monomer (EPDM) rubber. EPDM, a terpolymer composed of irregularly bonded ethylene, propylene, and diene, is employed in various products, as its mechanical properties, water resistance, and heat resistance are superior compared with those of conventional rubber [1-3].

EPDM has been extensively investigated with a focus on the reliability of products containing EPDM and analysis of their physical properties, which can be integrated in composite materials [4-6].

In contrast to plastic, EPDM exhibits high flexibility, elasticity, and elongation. Using injection molding, EPDM-based grommets can be fabricated. The process variables such as time and temperature during the EPDM-injection molding not only change the physical properties of the raw material but also affect the insertion and separations forces when a grommet product is molded and mounted on a car body. Using the design of experiments method [7-9], the major factors in the injection molding process were considered to analyze their effects on the physical properties of the obtained EPDM materials. Test pieces were prepared under different process conditions, tensile strength and elongation were measured, and their correlation was analyzed.

\section{Experimental setup}

\footnotetext{
${ }^{\mathrm{a}}$ Corresponding author : osjun@kongju.ac.kr
} 
In this study, test pieces were produced using a rubber injection molding machine with EPDM to analyze the physical properties of EPDM as a function of the injection molding process conditions. The physical properties of the produced test pieces were analyzed using a universal testing machine.

\subsection{Process variables}

In injection molding of a rubber material, the major process variables include temperature, time, and degassing conditions. After conducting a basic test on various process conditions, three process variables that can be easily regulated and have a significant effect on the test results were selected. An experiment plan was established using the design of experiment method. In particular, the full factorial design method was employed to identify the effects and relationships between the factors; a 3 -factor 2-level 2-time repetitive test was performed. Table 1 shows the established experiment plan based on a total of 16 experiments using three process variables. Based on the obtained experimental condition table, rubber injection molding was performed 16 times. The total number of produced rubber test pieces was 32, as there are two test pieces for each experimental condition (Fig. 1 (a)). The prepared rubber test pieces were cut for further studies of their physical properties, as shown in Fig. 1 (b).

Table 1. Experimental conditions for different process variable values according to DOE

\begin{tabular}{|c|c|c|c|c|c|c|c|}
\hline Run & $\begin{array}{c}\text { Temp. } \\
\left({ }^{\circ} \mathbf{C}\right)\end{array}$ & $\begin{array}{c}\text { Time } \\
(\mathbf{s e c})\end{array}$ & Degassing & Run & $\begin{array}{c}\text { Temp. } \\
\left({ }^{\circ} \mathbf{C}\right)\end{array}$ & $\begin{array}{c}\text { Time } \\
(\mathbf{s e c})\end{array}$ & Degassing \\
\hline 1 & 160 & 200 & $\mathrm{O}$ & 9 & 160 & 200 & $\mathrm{X}$ \\
\hline 2 & 160 & 200 & $\mathrm{O}$ & 10 & 160 & 200 & $\mathrm{X}$ \\
\hline 3 & 160 & 600 & $\mathrm{O}$ & 11 & 160 & 600 & $\mathrm{X}$ \\
\hline 4 & 160 & 600 & $\mathrm{O}$ & 12 & 160 & 600 & $\mathrm{X}$ \\
\hline 5 & 180 & 200 & $\mathrm{O}$ & 13 & 180 & 200 & $\mathrm{X}$ \\
\hline 6 & 180 & 200 & $\mathrm{O}$ & 14 & 180 & 200 & $\mathrm{X}$ \\
\hline 7 & 180 & 600 & $\mathrm{O}$ & 15 & 180 & 600 & $\mathrm{X}$ \\
\hline 8 & 180 & 600 & $\mathrm{O}$ & 16 & 180 & 600 & $\mathrm{X}$ \\
\hline
\end{tabular}

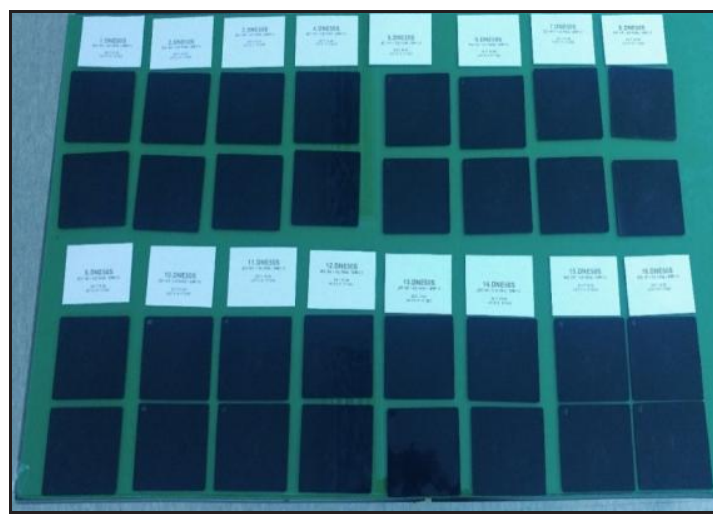

(a)
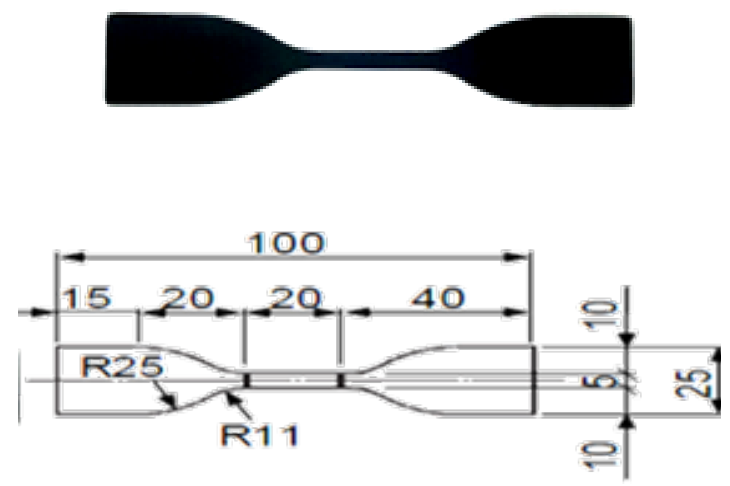

(b)

Figure 1. Specimens produced by various process conditions

\subsection{Physical property test}

In order to evaluate the physical properties of the materials, tensile strength and elongation were measured. In the tensile strength test, the tensile strength was calculated by measuring the maximum load at the moment when the test piece broke apart in the universal testing machine, and then dividing this value by the area of the cross section. The elongation was calculated by measuring the scale 
distance at the test piece. The test was performed at a speed of $500 \mathrm{~mm} / \mathrm{min}$. Figure 2 shows a photograph of the experimental setup where the tensile strength and elongation of the test pieces were measured, along with its conceptual diagram. Table 2 shows the results of the tensile strength and elongation measured for each process condition.
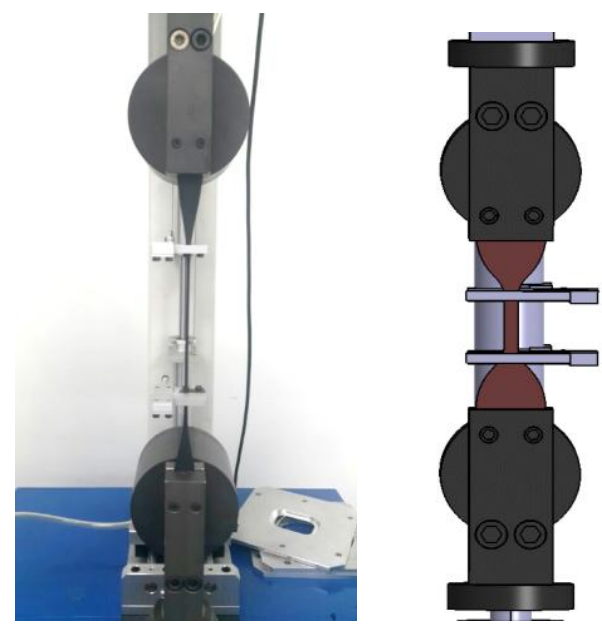

Figure 2. photograph of the experimental setup

Table 2. Formatting sections, subsections and subsubsections.

\begin{tabular}{|c|c|c|c|c|c|c|c|c|c|c|c|}
\hline Run & $\begin{array}{c}\text { Temp. } \\
\left({ }^{\circ} \mathrm{C}\right)\end{array}$ & $\begin{array}{c}\text { Time } \\
(\mathrm{sec})\end{array}$ & Degassing & $\begin{array}{c}\text { Tensile } \\
\text { strength } \\
\left(\mathrm{kgf} / \mathrm{cm}^{2}\right)\end{array}$ & $\begin{array}{c}\text { Elongation } \\
(\%)\end{array}$ & Run & $\begin{array}{c}\text { Temp. } \\
\left({ }^{\circ} \mathrm{C}\right)\end{array}$ & $\begin{array}{l}\text { Time } \\
(\mathrm{sec})\end{array}$ & $\begin{array}{c}\text { Tensile } \\
\text { Degassing }\end{array}$ & $\begin{array}{c}\text { Ttrength } \\
\left(\mathrm{kgf} / \mathrm{cm}^{2}\right)\end{array}$ & $\begin{array}{c}\text { Elongation } \\
(\%)\end{array}$ \\
\hline 1 & 160 & 200 & $\mathrm{O}$ & 114.4 & 969.0 & 9 & 160 & 200 & $\mathrm{X}$ & 107.0 & 968.3 \\
\hline 2 & 160 & 200 & $\mathrm{O}$ & 113.3 & 960.4 & 10 & 160 & 200 & $\mathrm{X}$ & 110.3 & 944.8 \\
\hline 3 & 160 & 600 & $\mathrm{O}$ & 136.6 & 853.9 & 11 & 160 & 600 & $\mathrm{X}$ & 137.7 & 851.5 \\
\hline 4 & 160 & 600 & $\mathrm{O}$ & 131.4 & 815.2 & 12 & 160 & 600 & $\mathrm{X}$ & 132.4 & 821.2 \\
\hline 5 & 180 & 200 & $\mathrm{O}$ & 134.2 & 840.5 & 13 & 180 & 200 & $\mathrm{X}$ & 130.5 & 838.7 \\
\hline 6 & 180 & 200 & $\mathrm{O}$ & 133.9 & 836.0 & 14 & 180 & 200 & $\mathrm{X}$ & 134.7 & 844.8 \\
\hline 7 & 180 & 600 & $\mathrm{O}$ & 137.0 & 775.0 & 15 & 180 & 600 & $\mathrm{X}$ & 132.9 & 749.7 \\
\hline 8 & 180 & 600 & $\mathrm{O}$ & 139.3 & 792.3 & 16 & 180 & 600 & $\mathrm{X}$ & 135.2 & 767.1 \\
\hline
\end{tabular}

\section{Analysis of the results}

An analysis of the main effects and their relationships was performed according to the experiment plan obtained using the design of experiment method. The factors that mainly affect the tensile strength and elongation were identified and their relationships were analyzed.

\subsection{Tensile strength as a function of the temperature, time and degassing conditions}

The effects of the temperature, time, and degassing conditions on the tensile strength were evaluated along with their relationships, as shown in Fig. 3(a). The results showed that the factor that has the biggest effect on the tensile strength was the time, followed by the temperature; degassing did not significantly affect the tensile strength. Figure 3(b) shows the relationships between the factors. It reveals that the temperature and time correlate with each other. Figure 3(c) shows the residual plot, which reveals that the residues are normally distributed, as the plot can be represented by almost a straight line. The model obtained by the analysis can be regarded to be valid as the plot showed a 
consistent distribution based on the average line. The distribution was normal, as no linear and constant terms were observed from the plot of residues and fitted values. The adjusted coefficient of determination of the experimental results was $93.2 \%$. Table 3 shows the results of the analysis of variance (ANOVA), where the correlations of the tensile strength with the process variables were evaluated.

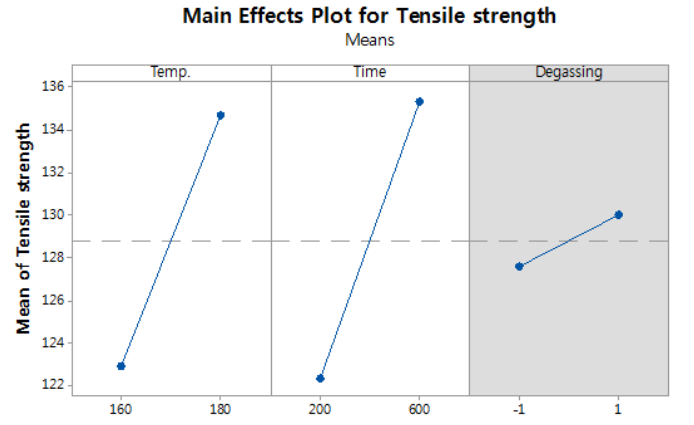

A gray background represents a term not in the model.

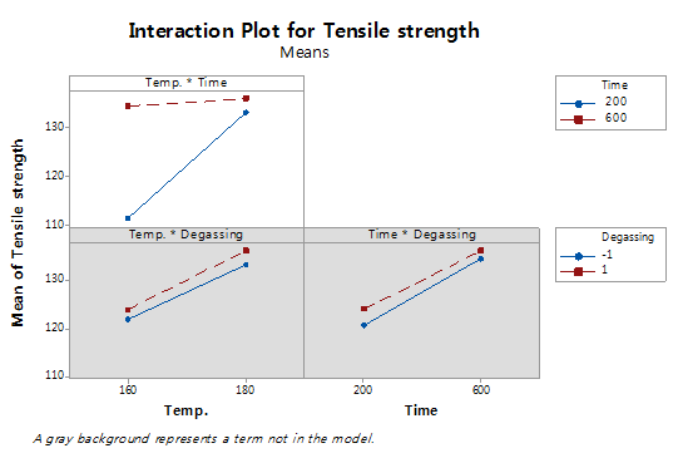

(b)

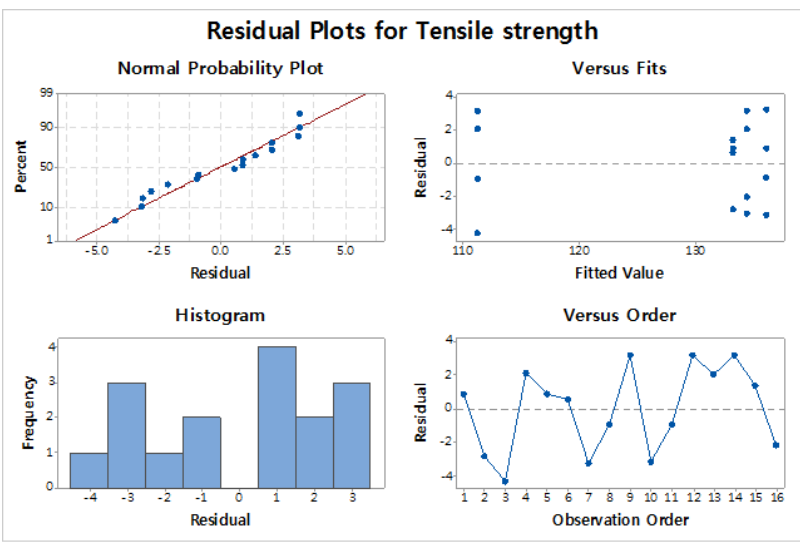

(c)

Figure 3. (a)Main effect plot, (b) Interaction plot, (c) Residual plot for tensile strength

Table 3. ANOVA of tensile stress

\begin{tabular}{|l|c|l|l|l|l|}
\hline Source & DF & Adj SS & Adj MS & F-Value & p-Value \\
\hline Model & 3 & 1658.17 & 552.725 & 69.95 & 0.000 \\
\hline Linear & 2 & 1237.93 & 618.963 & 78.33 & 0.000 \\
\hline Temp. $\left({ }^{\circ} \mathrm{C}\right)$ & 1 & 559.32 & 559.322 & 70.78 & 0.000 \\
\hline time $(\mathrm{s})$ & 1 & 678.6 & 678.602 & 85.88 & 0.000 \\
\hline 2-Way interactions & 1 & 420.25 & 420.25 & 53.18 & 0.000 \\
\hline $\mathrm{T}\left({ }^{\circ} \mathrm{C}\right)^{*}$ Time(sec) & 1 & 420.25 & 420.25 & 53.18 & 0.000 \\
\hline Error & 12 & 94.83 & 7.902 & & \\
\hline Total & 15 & 1753 & & & \\
\hline
\end{tabular}

\subsection{Elongation as a function of the temperature, time and degassing conditions}

Figure 4(a) shows the plot of the main factors that determine the elongation. The results reveal that both time and temperature affect the elongation, whereas degassing had only a small effect on the elongation. Figure 4(b) shows their correlations; it reveals that the temperature and time correlated 
with each other. Figure 4(c) shows the residual plot, which demonstrates the validity of the model. The adjusted coefficient of determination of the experimental results was $94.12 \%$. Table 4 shows the ANOVA results, obtained by analyzing the correlations of the elongation with the process variables. The results corresponding to a P-value larger than 0.05 were pooled into the error term, and only the significant terms were presented.

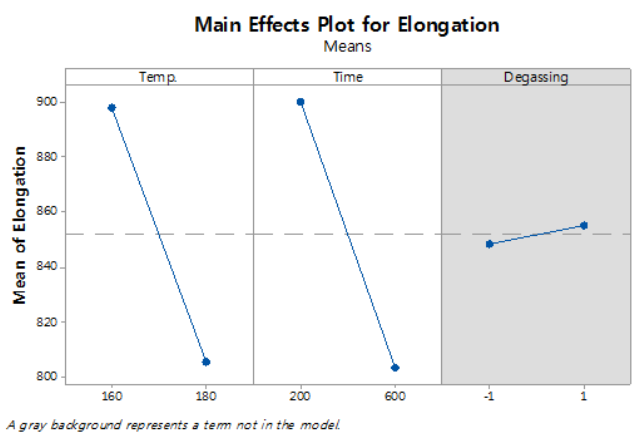

(a)

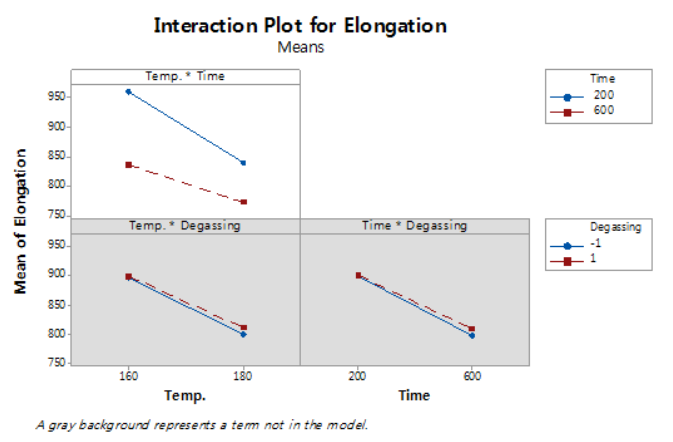

(b)

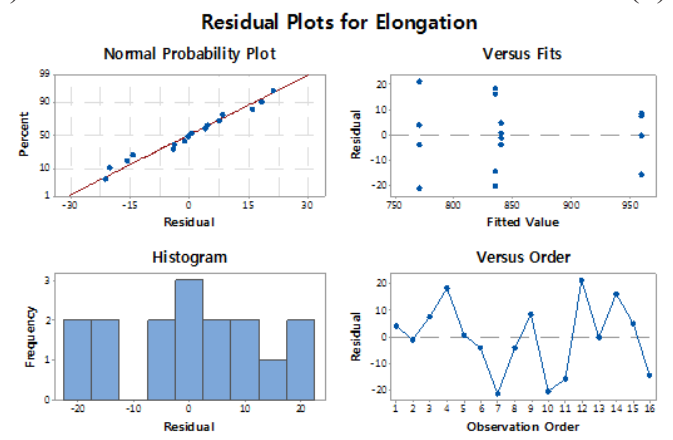

(c)

Figure 4. (a)Main effect plot, (b) Interaction plot, (c) Residual plot for elongation

Table 4. ANOVA of elongation

\begin{tabular}{|l|c|c|c|c|c|}
\hline Source & DF & Adj SS & Adj MS & F-Value & p-Value \\
\hline Model & 3 & 75096.2 & 25032.1 & 116.87 & 0.000 \\
\hline Linear & 2 & 71937.7 & 35968.9 & 167.93 & 0.000 \\
\hline $\mathrm{T}\left({ }^{\circ} \mathrm{C}\right)$ & 1 & 34243.5 & 34243.5 & 159.88 & 0.000 \\
\hline time $(\mathrm{s})$ & 1 & 37694.2 & 37694.2 & 175.99 & 0.000 \\
\hline 2-Way interactions & 1 & 3158.4 & 3158.4 & 14.75 & 0.034 \\
\hline $\mathrm{T}\left({ }^{\circ} \mathrm{C}\right)^{*}$ Time(sec) & 1 & 3158.4 & 3158.4 & 14.75 & 0.002 \\
\hline Error & 12 & 2570.2 & 214.2 & & \\
\hline Total & 15 & 77666.4 & & & \\
\hline
\end{tabular}

\section{Conclusions}

Using the design of experiment method, the main factors in the injection molding process were considered to analyze their effects on the physical properties of EPDM. Test pieces were produced at different process conditions, the tensile strength and elongation were measured, and their correlation was analyzed. Both temperature and time affected the tensile strength and elongation; however, the effect of degassing was insignificant. We aim to perform additional studies to reveal the optimal process conditions for achieving the desired values of tensile strength and elongation. 


\section{ACKNOWLEDGEMENTS}

This research was financially supported by the Ministry of Trade, Industry and Energy (MOTIE), Korea, under the "Regional Specialized Industry Development Program" supervised by the Korea Institute for Advancement of Technology (KIAT). (P0000164)

\section{References}

1. Oh, J. H., Kim, S. D., and Kim, J. S., J. of Korean Inst. of Resources Recycling, 12(5) (2003)

2. Song, H. S., and Hyun, J. C., Clean Tech., 7(2) (2001)

3. Folkes, M., and Hope, P. S., Blackie Academic Press, New York, (1992)

4. S.J Part, J.Y Kang, S.K. Hong, Polymer, 29,2 (2005)

5. K.Singh, T. Nanda, R Mehta, Composites Part A: Applied Science and Manufacturing, 103,(2017)

6. L.Cao,A.Zheng, X.Cao, D.Yuan,C.Xu,Y.Chen, Polymer Testing,62,(2017)

7. M. Brahmi, M. Ba, Y. Hidri, A. Hassen, J. of Molecular Structure, (2018)

8. M.Kala, M. V.Shaikh, M. Nivsarkr, J. of Pharmacological and Toxicological Methods, 82 (2016)

9. C.Chen, M.Chuang, Y. Hsiao, Y. Yang, C. T, Expert Systems with Applications, 36 (2009) 